\title{
Sorção do Sulfentrazone em Diferentes Tipos de Solo DETERMINADA POR BIOENSAIOS ${ }^{1}$
}

\author{
Sulfentrazone Sorption in Different Types of Soil by Bioassays
}

\author{
FREITAS, M.A.M. ${ }^{2}$, PASSOS, A.B.R.J. ${ }^{2}$, TORRES, L.G. ${ }^{2}$, MORAES, H.M.F. ${ }^{2}$, FAUSTINO, L.A. ${ }^{2}$, \\ ROCHA, P.R.R. ${ }^{3}$ e SILVA, A.A. ${ }^{2}$
}

\begin{abstract}
RESUMO - Objetivou-se com este trabalho avaliar o potencial de sorção do sulfentrazone em cinco diferentes tipos de solo, por meio da técnica do bioensaio. O comportamento do herbicida foi estudado nos seguintes tipos de solo: Planossolo Háplico, Argissolo Vermelho, Cambissolo Húmico, Neossolo Regolítico e Latossolo Vermelho-Amarelo, além de um controle, apenas com areia lavada. O experimento foi realizado no delineamento inteiramente casualizado, e os tratamentos foram constituídos de sete doses crescentes do sulfentrazone em cada um dos tipos de solo. Aos 21 dias após emergência, realizou-se a colheita da planta indicadora e foi determinada a massa da matéria seca, bem como a dose do herbicida capaz de reduzir em $50 \%$ o acúmulo de massa da matéria seca das plantas indicadoras $\left(C_{50}\right)$. Com esses dados calculou-se a relação de sorção (RS) do sulfentrazone, por meio da comparação da relação dos resultados da $\mathrm{C}_{50}$ de cada solo com a $\mathrm{C}_{50}$ obtida na areia lavada. Os valores de $\mathrm{RS}$ diferiram para os diferentes solos, apresentando a seguinte ordem crescente: Planossolo Háplico < Latossolo Vermelho-Amarelo < Argissolo Vermelho < Cambissolo Húmico < Neossolo Regolítico; os solos com maiores teores de matéria orgânica apresentaram os maiores RS e $\mathrm{pH}$ de cada solo. Conclui-se que a sorção do sulfentrazone é influenciada pelo teor de matéria orgânica e $\mathrm{pH}$ dos solos.
\end{abstract}

Palavras-chave: herbicida, planta indicadora, ensaio biológico.

ABSTRACT - The objective of this study was to evaluate the sorption potential of sulfentrazone in five different soil types by bioassays. Herbicide behavior was studied in the following soil types: Haplic Planosol, Red Acrisol, Humic Cambisol, Eutrophic Entisol and Red-Yellow Latosol, in addition to a control treatment, with washed sand only. The experiment was completely randomized, and treatments consisted of seven increasing doses of sulfentrazone in each of the soil types. Twentyone days after emergence, the indicator plant was collected and dry matter mass and herbicide dose capable of reducing the dry matter mass accumulation of the indicator plants by $50 \%\left(C_{50^{-}}\right)$ were determined. Based on these data, sorption rate (SR) of sulfentrazone was calculated by comparing the results of $C_{50}$ of each soil with the $C_{50}$ obtained in washed sand. Sorption rate values differed between the soils in the following ascending order: Haplic Planosol < Red-Yellow Latosol $<$ Red Acrisol < Humic Cambisol < Eutrophic Entisol; the soils with higher organic matter content showed the highest SR and pH. It was concluded that sulfentrazone sorption is affected by soil organic matter content and $\mathrm{pH}$.

Keywords: herbicide, indicator plant, biological test.

\section{INTRODUÇÃO}

O uso de agrotóxicos pode garantir eficiência no controle de pragas, doenças e plantas daninhas, no processo produtivo
(Vivian et al.,2006). Entretanto, existe grande preocupação mundial referente à contaminação ambiental causada pela utilização incorreta desses produtos (Law, 2001; Vivian et al.,2007).

1 Recebido para publicação em 22.5.2013 e aprovado em 1.2.2014.

2 Universidade Federal de Viçosa, Viçosa-MG, Brasil, <marcofreitas11@yahoo.com.br>; ${ }^{3}$ Universidade Federal de Roraima, Boa Vista-RR. 
A elevada utilização de herbicidas pode ser explicada pela presença constante das plantas daninhas nas lavouras, as quais, se não controladas na época adequada, podem causar perdas elevadas ou até mesmo totais na produtividade das culturas, devido à competição por água, luz e nutrientes (Silva et al.,2007).

Herbicidas que apresentam longo residual no solo, como o sulfentrazone, quando aplicados sem o conhecimento de suas interações com o ambiente, podem danificar a cultura tratada ou não ser eficientes no controle das plantas daninhas, além de contaminarem o solo e as águas superficiais e subterrâneas. Isso ocorre porque, independentemente de o herbicida ser aplicado em pré ou pós-emergência das plantas daninhas, o seu destino final geralmente é o solo (Law, 2001). Aproximadamente 60 a $70 \%$ do total de agrotóxicos aplicados nos campos agrícolas não atingem a superfície do alvo de interesse e, de forma direta ou indireta, atingem o solo - principal receptor e acumulador desses compostos (Law, 2001).

O herbicida, ao atingir o solo, pode ser sorvido, lixiviado ou degradado por processos físicos, químicos ou biológicos, além de poder ser absorvido pelas plantas (Silva et al., 2007). Esses processos são dependentes das características do solo, das condições climáticas e do herbicida (Brady, 1974). Desse modo, os conhecimentos básicos das interações dos herbicidas com o solo são de fundamental importância para compreender o comportamento desses compostos no meio ambiente, levando-se em consideração os principais processos de retenção, transformação e transporte (Wauchope et al.,2002).

A sorção refere-se à atração e retenção das moléculas ou íons à superfície dos sólidos e constitui um processo fundamental para a dinâmica dos compostos fitossanitários nos solos. Esses produtos apresentam comportamento complexo, resultante de numerosas interações com os constituintes das diferentes frações do solo. As frações orgânicas e a argila, associadas às características químicas do solo, principalmente o $\mathrm{pH}$, são as características que mais influenciam o processo de sorção e, consequentemente, a movimentação desses produtos no solo (Inoue et al., 2003;
Boivin et al., 2005; Rossi et al., 2005; Magalhães, 2007; Monquero et al., 2010). Assim, a sorção dos herbicidas pelos coloides dependerá da associação das características do solo com as do herbicida.

O sulfentrazone é um herbicida para aplicação em pré-emergência amplamente utilizado no Brasil, sendo recomendado para controle de plantas daninhas mono e dicotiledôneas na cultura de cana-de-açúcar, soja, eucalipto e café (ANVISA, 2011). Esse herbicida pertence ao grupo químico das triazolinonas e atua inibindo a enzima protoporfirinogênio oxidase (PROTOX), a qual é responsável pela oxidação do protoporfirinogênio à protoporfirina IX, na biossíntese da clorofila.

O sulfentrazone apresenta meia-vida estimada no solo ( $\left.t^{1 / 2} / 2\right)$ entre 110 e 280 dias, variando de acordo com as condições edafoclimáticas locais, sendo a atividade microbiológica seu mecanismo inicial de degradação (Vivian et al.,2006). Apresenta solubilidade em água de $490 \mathrm{mg} \mathrm{L}^{-1}$ e pressão de vapor de $1 \times 10^{-9}$ $\mathrm{mm} \mathrm{Hg}$ a $25^{\circ} \mathrm{C}$. No solo, a mobilidade é moderada, de baixa adsorção, com Koc de 43, pKa de 6,56 e Kow de 1,48 (Rodrigues \& Almeida, 2005).

Rodrigues \& Almeida (2005) também relataram que a eficiência do controle de plantas daninhas pelo sulfentrazone decresce com o aumento do teor de matéria orgânica no solo, indicando menor concentração do herbicida na solução do solo para exercer sua ação. A disponibilidade de água no solo está diretamente relacionada com a diminuição da concentração do sulfentrazone na sua camada superior, pois essa condição pode acelerar a degradação da molécula ou mesmo lixiviá-la para camadas mais profundas no solo. Esses autores relatam que degradação do sulfentrazone no solo normalmente é lenta e caracterizada pelo declínio gradual na concentração do herbicida no tempo.

Diante do exposto e considerando a carência de resultados de pesquisa com o sulfentrazone em solos tropicais, realizou-se este trabalho com o objetivo de avaliar o potencial de sorção do sulfentrazone nos solos: Planossolo Háplico, Argissolo Vermelho, Cambissolo Húmico, Neossolo Regolítico e 
Latossolo Vermelho-Amarelo, utilizando a técnica de ensaios biológicos.

\section{MATERIAL E MÉTODOS}

$\mathrm{Na}$ realização deste trabalho foram utilizados seis substratos, sendo cinco solos, além de um substrato inerte composto por areia lavada. Das cinco amostras dos solos, quatro foram provenientes do Estado do Rio Grande do Sul (Planossolo Háplico, Argissolo Vermelho, Cambissolo Húmico e Neossolo Regolítico) e um Latossolo Vermelho-Amarelo da Zona da Mata de Minas Gerais. As amostras de solo foram coletadas na profundidade de 0 a $20 \mathrm{~cm}$, destorroadas, secas à sombra, peneiradas em malha de $4 \mathrm{~mm}$ e, posteriormente, caracterizadas química e fisicamente (Tabelas 1 e 2). Para o preparo do substrato inerte, fez-se a incubação da areia com solução $\mathrm{HCl}(10 \%)$ por 24 horas, seguida de nova incubação por mais 24 horas com solução de $\mathrm{NaOH}$ e lavagem sequencial com água limpa em abundância até se atingir $\mathrm{pH} 7,0$.
Para obtenção da estimativa do potencial de sorção do sulfentrazone, foi conduzido um ensaio preliminar com cada substrato, a fim de definir a dose do herbicida capaz de inibir $50 \%$ do acúmulo de matéria seca da planta bioindicadora (Sorghum bicolor).

Os ensaios preliminares foram conduzidos em casa de vegetação no delineamento inteiramente casualizado com três repetições para cada substrato, utilizando doses crescentes do herbicida. Inicialmente, foram avaliadas as sete doses com amplitudes maiores definidas, tomando-se como base as características físicas e químicas de cada substrato. Esses experimentos foram repetidos ajustando-se as doses, até que fossem encontradas faixas de doses que permitissem definir as sete doses definitivas a serem utilizadas na curva para o cálculo da dose de herbicida capaz de reduzir em $50 \%$ o acúmulo de massa seca das plantas indicadoras. Após essa etapa, foram estipuladas as doses de sulfentrazone a serem avaliadas em cada substrato (Tabela 3), para

Tabela 1 - Características químicas dos solos: Planossolo Háplico, Argissolo Vermelho, Cambissolo Húmico, Neossolo Regolítico e Latossolo Vermelho-Amarelo, avaliados nos experimentos

\begin{tabular}{|c|c|c|c|c|c|c|c|c|c|c|c|c|c|c|}
\hline \multirow{2}{*}{ Solo } & \multirow{2}{*}{$\begin{array}{c}\mathrm{pH} \\
\left(\mathrm{H}_{2} \mathrm{O}\right)\end{array}$} & $\mathrm{P}$ & $\mathrm{K}$ & $\mathrm{Ca}$ & $\mathrm{Mg}$ & $\mathrm{Al}$ & $\mathrm{H}+\mathrm{Al}$ & SB & $(\mathrm{t})$ & $(\mathrm{T})$ & V & $\mathrm{m}$ & \multirow{2}{*}{$\frac{\mathrm{MO}}{\left(\mathrm{dag} \mathrm{kg}^{-1}\right)}$} & \multirow{2}{*}{$\frac{\text { P-rem }}{\left(\mathrm{mg} \mathrm{L}^{-1}\right)}$} \\
\hline & & \multicolumn{2}{|c|}{$\left(\mathrm{mg} \mathrm{dm}^{-3}\right)$} & \multicolumn{7}{|c|}{$\left(\mathrm{cmol}_{\mathrm{c}} \mathrm{dm}^{-3}\right)$} & \multicolumn{2}{|c|}{$(\%)$} & & \\
\hline Planossolo & 5,6 & 3,2 & 11 & 0,3 & 0,2 & 0,3 & 1,82 & 0,53 & 0,83 & 2,35 & 23 & 36 & 1,1 & 43,9 \\
\hline Argissolo & 5,2 & 1,5 & 27 & 1,2 & 0,6 & 2,1 & 6,77 & 1,87 & 3,97 & 8,64 & 22 & 53 & 2,1 & 20,8 \\
\hline Cambissol & 5,1 & 5,9 & 99 & 0,9 & 0,5 & 1,7 & 6,77 & 1,65 & 3,35 & 8,42 & 20 & 51 & 2,3 & 26,6 \\
\hline Neossolo & 5,1 & 9,1 & 115 & 3,3 & 0,7 & 0,7 & 8,09 & 4,29 & 4,99 & 12,38 & 35 & 14 & 5,1 & 23,5 \\
\hline Latossolo & 4,3 & 1,5 & 40 & 1,3 & 0,2 & 0,5 & 4,79 & 1,6 & 2,10 & 6,39 & 25 & 24 & 2,4 & 26,4 \\
\hline
\end{tabular}

Análises realizadas no Laboratório de Análises de Solo Viçosa, segundo metodologia da Empresa Brasileira de Pesquisa Agropecuária Embrapa (1997).

Tabela 2 - Características físicas dos solos: Planossolo Háplico, Argissolo Vermelho, Cambissolo Húmico, Neossolo Regolítico e Latossolo Vermelho-Amarelo, avaliados nos experimentos

\begin{tabular}{|l|r|r|r|l|}
\hline \multirow{2}{*}{ Solo } & Areia & Silte & Argila & \multirow{2}{*}{ Classe textural } \\
\cline { 2 - 4 } & \multicolumn{3}{|c|}{$(\%)$} & Areia Franca \\
\hline Planossolo & 87 & 4 & 9 & Franco-argiloso \\
\hline Argissolo & 42 & 20 & 38 & Franco Argiloarenoso \\
\hline Cambissolo & 62 & 12 & 26 & Franco-argiloso \\
\hline Neossolo & 51 & 17 & 32 & Argiloso \\
\hline Latossolo & 35 & 11 & 54 & Pipon \\
\hline
\end{tabular}

Análises realizadas no Laboratório de Análises de solos Viçosa LTDA- Determinações realizadas pelo método da pipeta (Embrapa, 1997; Ruiz, 2005). 
Tabela 3 - Doses do sulfentrazone ${ }^{1 /}\left(\mathrm{em} \mathrm{g} \mathrm{ha}^{-1}\right)$ aplicadas nos diferentes substratos

\begin{tabular}{|r|c|c|c|c|c|}
\hline \multicolumn{1}{|c|}{ Areia } & Planossolo & Argissolo & Cambissolo & Neossolo & Latossolo \\
\hline \multicolumn{7}{|c|}{ Doses $\left(\mathrm{g} \mathrm{ha}^{-1}\right)$} & 0 & 0 \\
\hline 0 & 0 & 0 & 100,0 & 100,0 & 12,5 \\
\hline 25 & 37,5 & 50,0 & 200,0 & 200,0 & 25,0 \\
\hline 50 & 75,0 & 100,0 & 300,0 & 300,0 & 50,0 \\
\hline 75 & 112,5 & 150,0 & 400,0 & 400,0 & 100,0 \\
\hline 100 & 150,0 & 200,0 & 500,0 & 500,0 & 150,0 \\
\hline 125 & 187,5 & 250,0 & 600,0 & 750,0 & 250,0 \\
\hline 150 & 225,0 & 300,0 & &
\end{tabular}

1/ Produto comercial Solara, contendo $500 \mathrm{~g} \mathrm{~L}^{-1}$ de sulfentrazone.

que fossem realizados os experimentos definitivos.

Nos experimentos definitivos, adotou-se a mesma metodologia dos ensaios preliminares no delineamento inteiramente casualizado com quatro repetições.

As unidades experimentais foram constituídas por vasos preenchidos com $280 \mathrm{~cm}^{3}$ dos substratos, compostos pelos diferentes tipos de solo e pelo substrato inerte. Foi feita a semeadura de oito sementes por vaso da espécie indicadora (Sorghum bicolor). Logo após, procedeu-se ao umedecimento dos substratos até próximo à capacidade de campo e à aplicação do herbicida nas diferentes doses (Tabela 3), utilizando um pulverizador pressurizado por $\mathrm{CO}_{2}$ comprimido, equipado com barra com dois bicos TT11002, amarelos, espaçados de $0,50 \mathrm{~m}$ e com volume de calda de $150 \mathrm{~L} \mathrm{ha}^{-1}$. Aos dez dias após semeadura realizou-se o desbaste, permanecendo apenas quatro plantas em cada vaso.

Os vasos receberam irrigação diariamente, mantendo-se sempre a umidade do solo próximo à capacidade de campo, e tratamento com solução de complementação nutricional equilibrada, diferenciada para cada um dos substratos.

Aos 21 dias após a semeadura, foi realizada a colheita dos experimentos, que consistiu no corte da parte aérea das plantas rente à superficie do substrato. Posteriormente, todo esse material foi seco em estufa de circulação forçada de ar $\left(70 \pm 2{ }^{\circ} \mathrm{C}\right)$ até atingir massa constante, sendo determinada a massa da matéria seca das plantas em balança com precisão de 0,001 g. Os valores de massa da matéria seca (MS) das plantas de sorgo foram transformados em porcentagem em relação à MS da testemunha, adotando-se $100 \%$ para MS da testemunha.

Os resultados obtidos foram interpretados, a partir da comparação dos valores da massa da matéria seca da parte aérea dos substratos tratados com herbicida com os do tratamento sem herbicida (dose zero), sendo submetidos à análise estatística, utilizando-se o modelo log-logístico não linear proposto por Seefeldt et al.(1995):

$$
Y=C+\frac{D-C}{1+\frac{(X)^{b}}{C_{50}}}
$$

em que $C$ e $D$ correspondem ao nível máximo e mínimo da curva de dose-resposta; $b$, ao

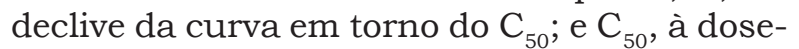
resposta referente à redução de $50 \%$ da massa de matéria seca da parte área da planta indicadora.

A partir dos dados obtidos de $\mathrm{C}_{50}$ para cada solo e para areia, calculou-se a relação de sorção (RS) do solo em relação à resposta obtida em areia para a espécie indicadora (Souza, 1994):

$$
R S=\frac{C_{50} \text { solo }-C_{50} \text { areia }}{C_{50} \text { areia }}
$$

Valores de $R S$ elevados indicam maior capacidade de adsorção do herbicida no solo e, consequentemente, menor potencial de lixiviação do composto no perfil do solo. 


\section{RESULTADOS E DISCUSSÃO}

As curvas de porcentagens de massa da matéria seca acumulada pelas plantas de sorgo em função das doses de sulfentrazone aplicado aos diferentes substratos, em relação à testemunha sem aplicação do herbicida, estão apresentadas na Figura 1, e as equações ajustadas para as curvas de sorção do herbicida nos diferentes solos são apresentadas na Tabela 4.
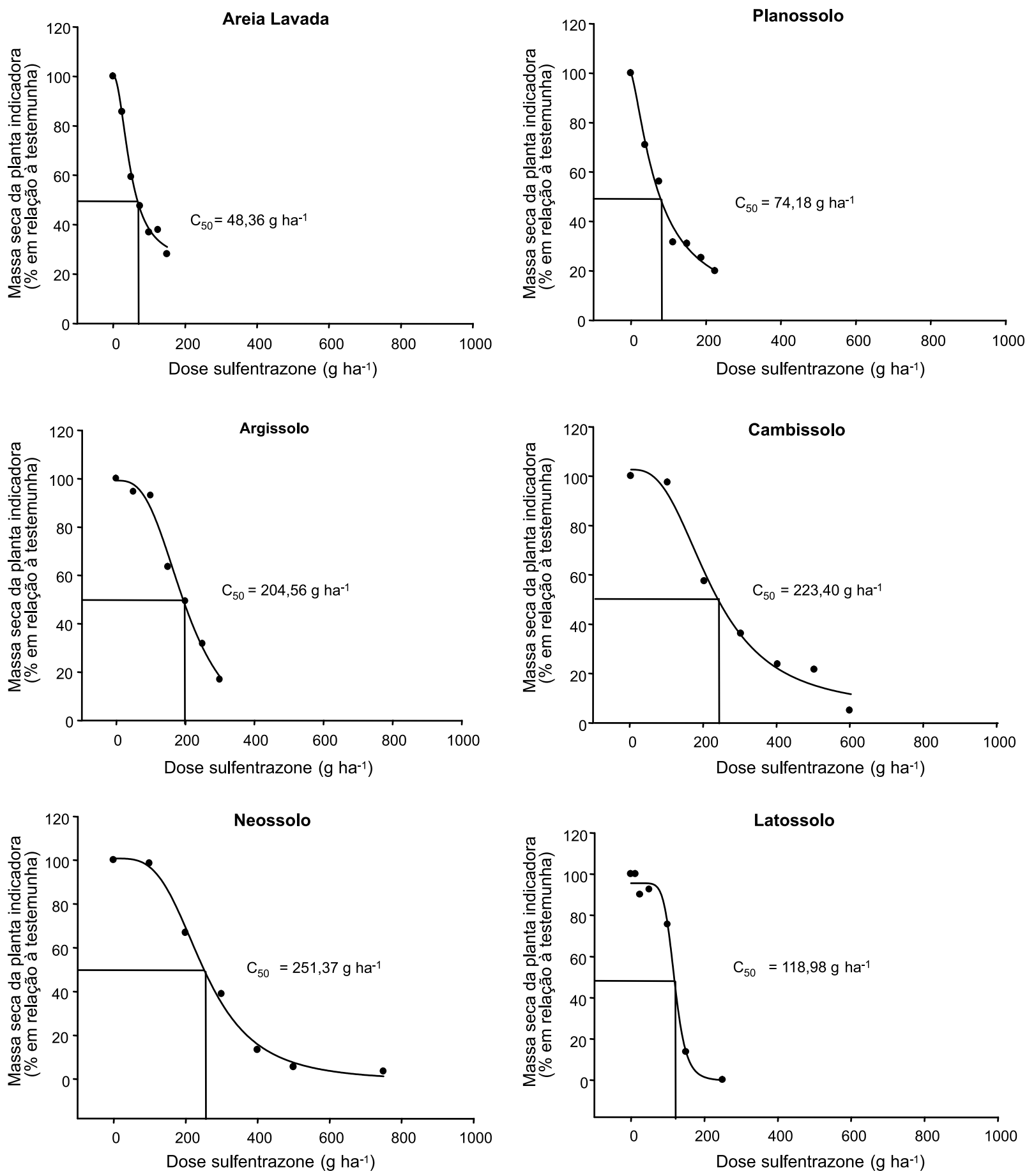

Figura 1 - Porcentagem da massa da matéria seca da parte aérea de sorgo em relação à massa da matéria seca da testemunha aos 21 dias após a emergência, em diferentes substratos, tratado com doses crescentes de sulfentrazone. 
Tabela 4 - Equações de regressão ajustadas e coeficientes de determinação da matéria seca da parte aérea de sorgo aos 21 dias após a emergência, em diferentes substratos, tratado com doses crescentes de sulfentrazone

\begin{tabular}{|l|c|c|}
\hline Substrato & Equação de Regressão & $\mathrm{R}^{2}$ \\
\hline Areia & $\mathrm{Y}=24,1575+\left(100,3159-24,1575 / 1+(\mathrm{x} / 46,3640)^{3,0455}\right.$ & 0,99 \\
\hline Planossolo & $\mathrm{Y}=2,7950+\left(99,7808-2,7950 / 1+(\mathrm{x} / 74,1767)^{1,3760}\right.$ & 0,99 \\
\hline Argissolo & $\mathrm{Y}=-8,1112+\left(99,2505+8,1112 / 1+(\mathrm{x} / 204,5623)^{2,9555}\right.$ & 0,99 \\
\hline Cambissolo & $\mathrm{Y}=5,3553+\left(102,6349-5,3553 / 1+(\mathrm{x} / 233,3961)^{2,7088}\right.$ & 0,99 \\
\hline Neossolo & $\mathrm{Y}=-0,9622+\left(100,7832+0,9622 / 1+(\mathrm{x} / 251,3659)^{3,4867}\right.$ & 0,99 \\
\hline Latossolo & $\mathrm{Y}=-0,3802+\left(95,6527+0,3802 / 1+(\mathrm{x} / 118,1209)^{7,1973}\right.$ & 0,99 \\
\hline
\end{tabular}

As concentrações do sulfentrazone capazes de inibir em $50 \%$ o acúmulo da massa de matéria seca das plantas de sorgo $\left(\mathrm{C}_{50}\right)$ e, também as relações de sorção do herbicida entre os diferentes solos e o substrato inerte, foram diferentes entre os solos (Figura 1). Isso ocorreu devido às características físicas e químicas específicas de cada substrato.

Essas observações ficam evidentes quando se analisam os dados da Tabela 5, que expressam a relação de sorção encontrada para os diferentes solos. O solo que apresentou a maior capacidade de adsorver o sulfentrazone foi o Neossolo Regolítico, que se caracteriza por apresentar o maior teor de matéria orgânica entre os solos avaliados (Tabela 5); neste solo a razão de sorção do sulfentrazone foi de 4,20. Por outro lado, a menor RS foi observada para o Planossolo Háplico $(0,53)$, o qual apresentou o menor teor de matéria orgânica, $1,1 \mathrm{dag} \mathrm{kg}^{-1}$, teor de argila de $9 \mathrm{dag} \mathrm{kg-1}^{-1}$ e $\mathrm{pH}$ de 5,6 (Tabela 5).

Esse fato evidencia a importância da matéria orgânica no processo de adsorção do sulfentrazone nos solos e confirma resultados encontrados por Brusseau \& Rao (1989). Esses autores ressaltam que o principal material adsorvente do solo é a matéria orgânica, por possuir sitios tridimensionais, formando ligações de hidrogênio que promovem a adsorção de compostos iônicos e não iônicos aos coloides orgânicos. Também Vieira et al. (1999) afirmaram que a matéria orgânica do solo é responsável pelo acréscimo na sorção de vários compostos, apresentando papel fundamental na adsorção de contaminantes ambientais, como herbicidas e metais pesados. Vivian et al.(2006) trabalharam com esse mesmo herbicida e encontraram resultado semelhante, considerando a matéria orgânica do solo como um dos principais fatores na adsorção do sulfentrazone pelo solo.

O potencial de sorção do sulfentrazone observado no Argissolo Vermelho e no Cambissolo Húmico foi bastante semelhante - confirmado pelos valores muito próximos de $\mathrm{C}_{50}$ e RS encontrados para esses substratos (Tabela 5). Esses dois solos apresentaram as características mais relevantes com relação à sorção do sulfentrazone, matéria orgânica e $\mathrm{pH}$, com valores muito similares: 5,2 e 5,1 para unidades de $\mathrm{pH}$ (Tabela 1), 2,1 e 2,3 dag kg-1 para teor de matéria orgânica e 204,56 e $223,40 \mathrm{~g} \mathrm{ha}^{-1}$ para dose capaz de inibir em 50\% o acúmulo de matéria seca das plantas indicadoras, no Argissolo Vermelho e Cambissolo Húmico, respectivamente (Tabela 5).

O Latossolo Vermelho-Amarelo, mesmo apresentando maior teor de argila, mostrou valor de $\mathrm{C}_{50}$ e RS inferior em relação aos outros substratos com teor de matéria orgânica similar (Argissolo e Cambissolo). Isso pode ser explicado pelo $\mathrm{pH}$ observado no Latossolo (Tabela 1). Com valores de pH próximos a 4,3, mesmo o sulfentrazone sendo um herbicida ácido fraco com constante de dissociação $(\mathrm{pKa}=6,56)$, o Latossolo está sujeito a sofrer protonação de parte de seus grupamentos, resultando na ocorrência de comportamento catiônico. Como se trata de um Latossolo muito intemperizado, com predominância de argilas 1:1, cuja estrutura contém hidroxilas de coordenação simples, as quais em valor de $\mathrm{pH}$ baixo formam cargas positivas devido à protonação (Hu \& Liu, 2003), ocorre a repulsão entre as cargas do solo e do herbicida, o que resulta na redução do potencial de sorção desse solo. Esse fato é semelhante ao ocorrido 
Tabela 5 - Características químicas e físicas dos solos e concentração do herbicida no solo que inibe 50\% do acúmulo de massa da matéria seca da planta indicadora $\left(\mathrm{C}_{50}\right)$ e razão de sorção (RS)

\begin{tabular}{|l|c|c|c|c|c|c|}
\hline Substrato & $\begin{array}{c}\mathrm{pH} \\
\left(\mathrm{H}_{2} \mathrm{O}\right)\end{array}$ & $\begin{array}{c}\text { Teor de argila } \\
\left(\text { dag kg }^{-1}\right)\end{array}$ & $\begin{array}{c}\text { M.O. } \\
\left(\mathrm{dag} \mathrm{kg}^{-1}\right)\end{array}$ & $\begin{array}{c}\text { CTC (T) } \\
\left(\mathrm{cmol}_{\mathrm{c}} \mathrm{dm}^{-3}\right)\end{array}$ & $\begin{array}{c}\mathrm{C}_{50} \\
\left(\mathrm{~g} \mathrm{ha}^{-1}\right)\end{array}$ & RS \\
\hline Areia lavada & 7,0 & 0 & 0 & 0 & 48,36 & - \\
\hline Planossolo & 5,6 & 9 & 1,1 & 0,83 & 74,18 & 0,53 \\
\hline Argissolo & 5,2 & 38 & 2,1 & 3,97 & 204,56 & 3,23 \\
\hline Cambissolo & 5,1 & 26 & 2,3 & 3,35 & 223,40 & 3,62 \\
\hline Neossolo & 5,1 & 32 & 5,1 & 4,99 & 251,37 & 4,20 \\
\hline Latossolo & 4,3 & 54 & 2,4 & 2,10 & 118,98 & 1,42 \\
\hline
\end{tabular}

no trabalho realizado por Borggard \& Streibig (1988) e Szmigielski et al. (2009), que, em bioensaios realizados com sulfentrazone em solos com diferentes características, observaram correlação não significativa entre os valores de $\mathrm{C}_{50}$ e o $\mathrm{pH}$ dos solos.

Em trabalhos realizados por Grey et al. (1997) e Ohmes \& Mueller (2007), a sorção do sulfentrazone nas partículas do solo foi superior em condições de alta matéria orgânica e argila e de baixo $\mathrm{pH}$.

Diante dos resultados, constatou-se que a sorção do sulfentrazone é influenciada pelo $\mathrm{pH}$ e teor de matéria orgânica do solo, fatores que devem ser levados em consideração na recomendação desse herbicida com o intuito de evitar a contaminação do solo e a fitotoxidez nas culturas subsequentes e de afetar o controle eficiente de plantas daninhas. A ordem crescente da relação de sorção do sulfentrazone nos solos estudados foi: Planossolo Háplico < Latossolo Vermelho-Amarelo < Argissolo Vermelho < Cambissolo Húmico < Neossolo Regolitico.

\section{LITERATURA CITADA}

AGÊNCIA NACIONAL DE VIGILÂNCIA SANITÁRIA ANVISA. Disponível em: <http://portal.anvisa.gov.br/wps/ portal/anvisa/home/agrotoxicotoxicologia>. Acesso em: 5 maio 2011.

BOIVIN, A. et al.Bentazone adsorption and desorption on agricultural soils. Agron. Sust. Develop., v. 25, n.2, p. 309$315,2005$.

BORGGAARD, O. K.; STREIBIG, J. C. Chlorsulfuron adsorption by humic acid, iron oxides, and montmorillonite. Weed Sci.,v. 36, n. 4, p. 530-534, 1988.
BRADY, N. C. The nature and properties of soils. 8.ed. New York: Macmillan, 1974. 639 p.

BRUSSEAU, M. L.; RAO, P. S. C. The influence of sorbate organic matter interactions in sorption nonequilibrium.

Chemosphere, v. 17, p. 1691-1706, 1989.

EMPRESA BRASILEIRA DE PESQUISA AGROPECUÁRIA - EMBRAPA. Centro Nacional de Pesquisa de Solos. Manual de métodos de análise de solos. 2.ed. Rio de Janeiro: 1997. 212 p.

GREY, T. L. et al.Sulfentrazone adsorption and mobility as affected by soil and pH. Weed Sci., v. 45, n.5, p. 733-738, 1997.

HU, Y.; LIU, X. Chemical composition and surface property of kaolins. Miner. Eng., v. 16, p. 1279-1284, 2003.

INOUE, M. H. et al.Critérios para avaliação do potencial de lixiviação de herbicidas comercializados no estado do Paraná. Planta Daninha, v. 21, n. 2, p. 313-323, 2003.

LAW, S. E. Agricultural electrostatic spray application: a review of significant research and development during de $20^{\text {th }}$ century. J. Electrostatic, v. 51-52, p. 25-42, 2001.

MAGALHÃES, E. J. Sorção de ametryn em frações de solo associadas à matéria orgânica. 2007. $116 \mathrm{f}$. Dissertação (Mestrado em Agroquímica) - Universidade Federal de Viçosa, Viçosa-MG, 2007.

MONQUERO P. A. et al.Lixiviação e persistência dos herbicidas sulfentrazone Imazapic. Planta Daninha, v. 28, n. 1, p. 185-195, 2010.

OHMES, G. A.; MUELLER, T. C. Sulfentrazone adsorption and mobility in surface soil of the southern United States. Weed Technol., v. 21, n. 3, p. 796-800, 2007.

RODRIGUES, B. N.; ALMEIDA, F. S. Guia de herbicidas. Londrina, 2005. 591 p.

Planta Daninha, Viçosa-MG, v. 32, n. 2, p. 385-392, 2014 
ROSSI, C. V. S. et al.Mobilidade do sulfentrazone em Latossolo Vermelho e em Chernossolo. Planta Daninha, v. 23, n. 3, p. 701-710, 2005.

RUIZ, H. A. Incremento da exatidão da análise granulométrica do solo por meio da coleta da suspensão (silte + argila). R. Bras. Ci. Solo, v. 29, n. 2, p. 297-300, 2005.

SEEFELDT, S. S. et al. Log-logistic analysis of herbicide dose-response relationship. Weed Technol., v. 9, n. 2, p. 218-227, 1995.

SILVA, A. A. et al.Herbicidas: comportamento no solo. In: SILVA, A. A.; SILVA, J. F. (Ed.). Tópicos em manejo de plantas daninhas. Viçosa, MG: Universidade Federal de Viçosa, 2007. p. 189-248.

SOUZA, A. P. Atividade de oxyfluorfen, 2,4-D e glyphosate em solos de diferentes texturas na presença e na ausência de composto orgânico. 1994. 71 f. Dissertação (Mestrado em Solos e Nutrição de Plantas) - Universidade Federal de Viçosa, Viçosa, MG, 1994.
SZMIGIELSKI, A. M. et al.Development of a laboratory biossay and effect of soil properties on sulfentrazone phytotoxicity in soil. Weed Technol., v. 23, p. 486-491, 2009.

VIEIRA, E. M. et al.Estudo da adsorção/dessorção do ácido 2,4 diclorofenoxiacético (2,4 D) em solo na ausência e presença de matéria orgânica. Química Nova, v. 22, n. 3, p. 305-308, 1999.

VIVIAN, R. et al.Persistência de sulfentrazone em Argissolo Vermelho-Amarelo cultivado com cana-de-açúcar.

Planta Daninha, v. 24, n. 4, p. 741-750, 2006.

VIVIAN, R. et al.Persistência e lixiviação de ametryn e trifloxysulfuron-sodium em solo cultivado com cana-deaçúcar. Planta Daninha, v. 25, n. 1, p. 111-124, 2007.

WAUCHOPE, R. D. et al.Pesticide soil sorption parameters: theory, measurement, uses, limitations and reliability. Pest Manag. Sci., v. 58, n. 5, p. 419-445, 2002. 